\title{
O papel do ambiente escolar na cultura alimentar Kaingang: o caso da Terra Indígena Rio das Cobras, PR
}

\author{
The role of the school environment in food culture Kaingang: the Rio das Cobras \\ Indigenous Land case, PR
}

\section{Le rôle de l'environnement scolaire dans la culture alimentaire Kaingang: le cas de Terre Indigene Rio das Cobras, PR}

\author{
El papel del medio ambiente escolar en la cultura alimentaria Kaingang: el caso \\ de la Tierra Indígena Rio das Cobras, PR
}

\author{
Suzana Kagmu Mineiro ${ }^{1}$ \\ Rozane Marcia Triches ${ }^{1}$
}

Recebido em 27/07/2017; revisado e aprovado em 20/12/2017; aceito em 27/12/2017

DOI: http://dx.doi.org/10.20435/inter.v19i4.166

Resumo: Este artigo busca analisar o papel da escola indígena na valorização/revitalização da cultura alimentar na Terra Indígena Rio das Cobras em Nova Laranjeiras, PR. Foi realizada uma pesquisa qualitativa, em cinco escolas Kaingang, por meio de entrevista semiestruturada e verificação do cardápio escolar. As escolas perpetuam, no cotidiano dos alunos ambientes que propiciam a aculturação e globalização dos hábitos alimentares, sem preocupações com a manutenção de sua cultura.
\end{abstract}

Palavras-chave: indígenas; cultura alimentar; alimentação escolar.

Abstract: This article analyzes the role of the indigenous school in the valorization/revitalization of food culture in the Rio das Cobras Indigenous Land in Nova Laranjeiras, PR. A qualitative research was carried out in five Kaingang schools, through a semi-structured interview and verification of the school menu. Schools perpetuate in the daily life of students, environments that promote the acculturation and globalization of eating habits, without worrying about the maintenance of their culture.

Keywords: indigenous; food culture; school feeding.

Résumé: Cet article vise à analyser le rôle de l'école indigène dans la récupération/revitalisation de la culture alimentaire dans le terre indigene Rio das Cobras à Nova Laranjeiras, PR. Une enquête qualitative a été menée dans cinq écoles Kaingang, par entrevue semi-structurée et la vérification des menus scolaires. Les écoles perpétuent la vie quotidienne des étudiants, des environnements qui favorisent l'acculturation et la mondialisation des habitudes alimentaires, sans se soucier de maintenir leur culture.

Mots-clés: indienne; culture alimentaire; I'alimentation scolaire.

Resumen: Este artículo busca analizar el papel de la escuela indígena en la valorización/revitalización de la cultura alimentaria en la Tierra Indígena Río das Cobras en Nova Laranjeiras, PR. Se realizó una investigación cualitativa, en cinco escuelas Kaingang, a través de entrevista semiestructurada y verificación del menú escolar. Las escuelas perpetúan en el cotidiano de los alumnos, ambientes que propician la aculturación y globalización de los hábitos alimenticios, sin preocupaciones por el mantenimiento de su cultura.

Palabras clave: indígenas; cultura alimentaria; alimentación escolar.

\section{INTRODUÇÃO}

A Constituição Federal de 1988 é conhecida pela sociedade brasileira por trazer, em suas normativas, direitos para a promoção da cidadania. Um desses direitos é o direito ao alimento, que foi incluído em 2010, a partir da Emenda Constitucional n. 64. Nesse novo contexto, além de promover a subsistência, o acesso ao alimento deve respeitar o aspecto sociocultural da sociedade, garantindo assim a valorização do indivíduo e dos processos históricos que constituem sua identidade.

\footnotetext{
1 Universidade Federal da Fronteira Sul (UFFS), Chapecó, Santa Catarina, Brasil.
} 
Atualmente, segundo Engel e Almeida (2015, p. 230), o momento histórico é moldado pela globalização, na qual as "culturas se diluem uma nas outras, transformando-se ininterruptamente", enfatizando a perda das peculiaridades de uma determinada sociedade e sua cultura. Portanto, para os autores, trabalhar em prol do resgate de identidades culturais é um desafio. No que tange aos povos indígenas, estes "vêm elaborando ao longo de sua história, complexos sistemas de pensamento e modos próprios de produzir, armazenar, expressar, transmitir, avaliar e reelaborar seus conhecimentos e suas concepções sobre o mundo, o homem e o sobrenatural" (BRASIL, 1988, p. 22). Porém, com o avanço das culturas homogeneizantes pautadas na modernidade sobre as terras indígenas, suas tradições passaram a sofrer influência não indígena cada vez mais frequente, favorecendo a perda de particularidades de sua cultura, inclusive a alimentar.

Partindo desse ponto, esta pesquisa buscou compreender qual tem sido o papel do ambiente escolar na cultura alimentar Kaingang, considerando que a escola é um lugar onde as práticas pedagógicas devem voltar seu olhar para a cultura, sendo que a alimentação é parte intrínseca desse construto. Portanto desconsiderá-la é desconsiderar um componente importante da identidade e da estrutura de um povo.

Para tanto, escolheu-se como local de investigação a Terra Indígena Rio das Cobras, localizada no município e Nova Laranjeiras, PR. Essa localidade foi escolhida por estar localizada entre uma rodovia federal e outra estadual (onde os indígenas vendem seus produtos artesanais) e devido à sua proximidade com o meio urbano e o contato quase que diário com o não indígena.

Este artigo está estruturado em quatro partes além desta introdução. A primeira realiza uma contextualização sobre o indígena e sua relação com a natureza, com a escola e com a cultura alimentar. Na sequência, apresenta-se a metodologia do estudo e, posteriormente, um pouco do histórico da implantação da escola na reserva indígena e sua cultura alimentar. A seguir, enfatiza-se como o ambiente escolar tem propiciado a valorização dessa cultura ou não, encerrando com as considerações finais.

\section{O INDÍGENA E SUA RELAÇÃO COM A NATUREZA E COM A CULTURA}

Ao longo dos anos, os povos tradicionais construíram saberes em relação a sua subsistência e sobrevivência, em que estabeleceram uma dinâmica constante e harmônica com a natureza (ALTIERI, 2012). No entanto, no Brasil, desde a sua colonização, essa relação sofreu mudanças que interferiram drasticamente na paisagem natural com a devastação das florestas para instituir cidades e lavouras (DEAN, 2004). Isto foi mais evidenciado a partir de 1960, com o início a Revolução Verde. Esta foi caracterizada pela introdução tecnológica na agricultura, como a modificação de sementes, fertilização do solo, utilização de agrotóxicos e mecanização no campo, com o objetivo precípuo de aumentar a produtividade agrícola, enfrentando assim o problema da fome. Embora o Brasil tenha se tornado um dos maiores produtores e exportadores do mundo, esse progresso técnico na agricultura não trouxe muitos benefícios para a sociedade brasileira, visto que a fome continuou, os pequenos agricultores foram migrando para as cidades por não conseguirem se adaptar às inovações, as matas foram se transformando em campos de monoculturas e os indígenas foram perdendo suas terras e, portanto, seus meios de sobrevivência. Essa situação foi sendo agravada, influenciando os modos de vida da sociedade brasileira e a dos povos indígenas (MOREIRA, 2000).

No entanto, em meados de 1980, estudiosos e ambientalistas iniciaram a marcha em prol da importância das florestas, buscando interromper o desmatamento e os problemas criados 
pelo homem na natureza (DEAN, 2004). Nesse ínterim, a agroecologia surge como ciência integradora que reconhece e se nutre dos saberes e conhecimentos dos povos tradicionais (CAPORAL; COSTABEBER; PAULUS, 2006, p. 46). Essa nova postura em relação aos povos tradicionais implicou considerá-los como atores de tecnologias mais afins à manutenção ambiental, com uma relação muito mais preservadora dos recursos naturais. No entanto muitos povos indígenas foram perdendo essa essência com a aculturação que foram sofrendo com o passar dos anos. Dentre os fatores responsáveis por esse movimento, pode-se considerar os processos de "educação" formal como fundamentais.

A educação escolar para o indígena, desde a colonização, tinha como características o caráter homogeneizador. Em meados de 1970, movimentos indigenistas e simpatizantes começaram uma luta contra o processo de dominação das ações integracionistas do Estado brasileiro (BRASIL, 2007). Dentro desse novo contexto, a Constituição Federal de 1988 é contemplada com normativas legais a favor da causa indígena, consequentemente, a educação escolar indígena passa por mudanças significativas no cenário brasileiro (BRASIL, 1988). Esse cenário ganha força com a Lei de Diretrizes e Bases da Educação Nacional (LDB 9394/96) (BRASIL, 1996) garantindo que a escola possa ser pensada pelos indígenas, e não para os indígenas, quando a valorização a revitalização e o resgate devem ser uma realidade. Assim, em 1998 é produzido o Referencial Curricular para as Escolas Indígenas (RCNEI) a fim de promover direcionamentos para uma educação escolar indígena específica, diferenciada e de qualidade (BRASIL, 1998).

É importante pontuar que a escola indígena é um lugar onde as dinâmicas e interações de saberes acontecem e se materializam. Para tanto, Alarcão (2001) afirma que a escola é promotora de conhecimentos e, que, diante disso, a sociedade deve refletir novas formas de pensar a escola, construindo sua função social. Ou seja, contribuindo na formação do estudante, na perspectiva de ele ter consciência de sua importância enquanto indivíduo na sua família e na comunidade e, enquanto sujeito intervindo de forma crítica na realidade. Portanto, no plano social, a escola deve estimular no educando, a partir da reflexão sobre sua cultura, cuidados com a natureza, questões alimentares, entre outros, a consciência do que seja viver bem em sociedade.

A escola, dentro dessa nova realidade de afirmação cultural, é de grande importância, pois é por meio dela que o histórico de subordinação à sociedade não-indígena pode ser superado. Para tanto, a escola indígena deveria ser pensada do ponto de vista sociocultural, político e econômico da sociedade em que está inserida e, nesse sentido, a educação escolar indígena teria o propósito de fortalecer a identidade étnica e ajudar no enraizamento da cultura dos povos indígenas.

Mais especificamente, um dos elementos fundantes da cultura é a alimentação. Atualmente, o tema da alimentação vem ganhando espaço nas discussões sobre a situação dos povos indígenas devido ao aumento de problemas nutricionais, principalmente em crianças, e de doenças ligadas à má alimentação, como a diabetes e hipertensão arterial nos adultos, considerados males adquiridos no processo de integração à sociedade não indígena (BRASIL, 2012). Esses dados apenas refletem as consequências do que vem ocorrendo nos últimos anos - uma grande mudança no tipo de alimentação desses povos, de modo a tornar-se cada vez mais semelhante à alimentação dos não índios (BRASIL, 2012, p. 160). Isto demonstra como as concepções da sociedade não indígena dominaram os modos de vida dos povos indígenas, afetando significativamente essas populações e o papel da escola na revisão desses valores. 


\section{METODOLOGIA}

No estado do Paraná, três povos indígenas fazem parte da população, os Guarani, os Kaingang e os Xetá. Essas três etnias vivem em 17 terras indígenas. Essas comunidades são basicamente produtoras de roças de subsistência e criação de animais de pequeno porte. A renda é complementada por subsídios de programas do governo, aposentadorias, produção e venda de artesanatos, além do salário recebido por serem alguns funcionários públicos, principalmente professores (ALMEIDA, 2014). Sobre a propriedade da terra, esta é de uso coletivo, onde todo o território constitui espaço de caça e coleta sem que essa exploração denote direito sobre a propriedade (ROCHA, 2008).

Os Xetá pertencem ao tronco linguístico Tupi-Guarani e foram contatados na região da serra dos Dourados no noroeste do Paraná. em 1950. com aproximadamente duzentos indivíduos. Atualmente existem apenas seis remanescentes, todos parentes e residentes em terras indígenas Kaingang (IANDÉ, 2008). Os Guarani também são do grupo do tronco linguístico TupiGuarani. Povoam regiões do Brasil, Argentina, Uruguai e Paraguai. Os Guarani habitavam desde o litoral, estendendo-se às florestas subtropicais do planalto, até o rio Paraná à oeste (ARAÚJO; FAUSTINO; NOVAK, 2009).

Os Kaingang pertencem à família linguística Jê e estão dispersos em vários subgrupos na zona oeste dos Estados de São Paulo, Paraná, Santa Catarina e Rio Grande do Sul (D’ANGELIS; VEIGA, 2003). Os Kaingang são divididos em duas metades tribais, Kamé e Kairu, os quais definem os papéis sociais e cerimônias de cada indivíduo nas atividades sociais (PINHEIRO, 2013). Sobre as tradições Kaingang, estas são transmitidas, em sua grande maioria, por tradição oral (FAGUNDES; FARIAS, 2011).

Em relação à economia Kaingang, Becker (1976, p. 17), a descreve como:

A economia do grupo era baseada na colheita, especialmente de pinhões, do que faziam provisão, e na caça que lhes era garantida no território de caça, considerado propriedade coletiva para cada grupo; praticavam também uma agricultura incipiente. Seu regime alimentar constava de carne de caça e peixe, de mel e frutos silvestres, abóbora e milho; a única bebida alcoólica era a chicha por eles fabricada; depois do contato com o branco aderiram ao uso da cachaça.

Na contemporaneidade, a economia capitalista faz parte do cotidiano da maioria das sociedades e é também uma realidade encontrada nas terras indígenas Kaingang. Isto não significa que o indígena deixou suas raízes, mas ressignificou seus conhecimentos frente ao mundo moderno. Portanto é necessário compreender as novas configurações do espaço sociocultural dos povos indígenas contemporâneos (PORTO ALEGRE, 2008).

Diante desse panorama, este estudo buscou realizar pesquisa qualitativa, estudando o caso da Terra Indígena Rio das Cobras localizada na região Centro-Oeste do Paraná. Essa terra indígena foi escolhida por ser a maior do Estado do Paraná, tendo sua extensão distribuída entre o município de Nova Laranjeiras e o município de Espigão Alto do Iguaçu.

A população indígena da Terra Indígena Rio das Cobras está concentrada no município de Nova Laranjeiras e é onde está o maior percentual de indígenas no Paraná, 19,9\% dos habitantes, residindo aproximadamente 2.239 indígenas Kaingang e Guaranis Kaiowá, segundo os dados do Instituto Brasileiro de Geografia e Estatística (IBGE) de 2010. No município de Espigão Alto do Iguaçu residem 465 indígenas Guarani Kaiowá, ou seja, 5,8\% da população total do município (IBGE, 2010 ). Ao todo, na Terra Indígena Rio das Cobras residem 2.704 indígenas. 
Sobre a área territorial, esta é composta de 18.681 hectares, onde é encontrada uma extensão considerável de floresta ombrófila mista constituída por araucárias e inúmeras espécies de plantas com utilidades que vão desde alimentação, saúde, moradia, artesanato dentre outras. A área territorial é de usufruto exclusivo e coletivo dos indígenas e sob responsabilidade da FUNAI. No dia 18/05/1949 o Diário Oficial da União publicou a demarcação da Terra Indígena Rio das Cobras, sendo homologado em 1986.

A pesquisa foi realizada em cinco das sete escolas estaduais Kaingang da Terra Indígena Rio das Cobras, as quais se encontram localizadas nos seguintes locais: duas na comunidade Sede, uma na comunidade Taquara, uma na comunidade Trevo e uma na comunidade do Campo do Dia. Estas foram escolhidas por conveniência, em função do acesso e da anuência dos líderes da comunidade e diretores das escolas em participar da pesquisa.

A coleta de dados se deu a partir de duas fontes: 1) dados primários: observação, investigação narrativa dos atores da comunidade escolar, por meio de entrevista semiestruturada com anciãos da comunidade, resgatando assim memórias históricas da cultura alimentar, implantação da escola e da alimentação escolar desta terra indígena. Também foram realizadas entrevistas semiestruturadas com outros atores contemporâneos das cinco escolas investigadas; e 2) dados secundários: pesquisa bibliográfica e documental como legislações e cardápios escolares.

Meihy, em seu Manual de história oral (2005), destaca que a história oral é uma prática de apreensão de narrativas feitas através do uso de meios eletrônicos e destinada a recolher testemunhos, promover análises de processos sociais do presente e facilitar o conhecimento do meio imediato. Com relação ao seu uso, neste estudo, foi escolhida, dentre as existentes, a técnica da História Oral de Vida, que constitui a narrativa do conjunto de experiências de uma pessoa. Por isso, a escolha dos entrevistados não pode ser aleatória, pois é fundamental a listagem de atores que poderão fornecer contribuições que podem variar de úteis a imprescindíveis ao desvelamento do tema. Dessa forma, em relação aos anciãos, foram escolhidas três pessoas. A primeira delas se caracteriza por ser uma das moradoras mais antigas da reserva indígena e os outros dois por serem os primeiros professores indígenas do local.

Para buscar informações sobre a valorização da cultura alimentar indígena nas escolas na atualidade, buscou-se também entrevistar atores sociais contemporâneos. Para tanto, foram entrevistados uma liderança, um pai de aluno, um gestor, uma merendeira, um professor indígena e um professor não-indígena de cada comunidade onde cada escola se encontrava. Estes foram escolhidos, ou por serem únicos (liderança, gestor, merendeira), ou pela facilidade de acesso (pai de aluno), ou pela aceitação em falar (professores). Também se entrevistou a nutricionista responsável pela alimentação escolar do Estado do Paraná e a coordenadora da educação escolar indígena do Núcleo Regional de Educação de Laranjeiras do Sul, totalizando 35 entrevistados.

Em relação aos cardápios, estes foram solicitados nas escolas e/ou no Núcleo Regional de Educação, e foram coletados os seguintes dados: os tipos de produtos/preparações presentes, procedência, quem abastece a escola e de que forma (se existem indígenas dentre os fornecedores), quem são as cozinheiras, quem formula o cardápio, se ele é seguido, e principalmente, se atendem as especificidades culturais do alunado.

A análise dos dados foi feita a partir da transcrição, leitura e sistematização das entrevistas e documentos. Foram destacados os pontos principais de cada entrevista, organizando um quadro com recortes por temas, sendo acrescentadas informações adicionais obtidas pelas observações 
e trabalho de campo. Em relação aos cardápios escolares, a sua análise de adequação cultural foi feita de forma descritiva.

\section{DO PASSADO AO PRESENTE: O PAPEL DA ESCOLA NA CULTURA ALIMENTAR KAINGANG}

A memória é a base para a construção da identidade histórica do indivíduo, é o alicerce que liga o presente, o passado e o futuro ${ }^{2}$. O conhecimento se faz da memória, pois, ao relacionar o antes, o durante e o depois de um determinado acontecimento ou situação, é que é possível construir o conhecimento. A história oral traz à tona momentos que não foram deixados no esquecimento e, assim, torna-se conhecimento. Relembrar vivências em favor do conhecimento transcreve a resistência do saber acumulado, em que, por meio da memória e da prática da história oral, é possível refletir e compreender sobre o contexto de uma determinada situação. qqq

Assim sendo, para fazer uma relação com o presente e o passado, foi necessário conhecer as memórias históricas sobre a implantação da escola na Terra Indígena, a alimentação tradicional da localidade e a alimentação escolar Kaingang, observando suas mudanças no tempo.

\subsection{As mudanças na cultura alimentar indígena}

Para identificar as mudanças relativas à cultura alimentar na Terra Indígena Rio das Cobras, $\mathrm{PR}$, foram ouvidos os dois primeiros professores indígenas (José e Antônia ${ }^{3}$ ), denominados monitores e uma anciã da comunidade, Dona Maria4.

Por meio das falas de Dona Maria (72 anos) foram observadas questões referentes à economia, modos de vida e especificamente da cultura alimentar Kaingang. Sobre a Terra Indígena Rio das Cobras, ela relata que "[...] quando era mais nova no Rio das Cobras tinham poucas famílias, elas viviam nas pequenas comunidades que existem até hoje, mas aumentaram bastante, tiveram muitos filhos".

Os dois professores entrevistados (José e Antônia) relataram sobre aspectos a partir do ano de 1976, ano em que passaram a lecionar na primeira escola dessa terra indígena, pois eram Kaingangs naturais do Rio Grande do Sul. A primeira dificuldade encontrada, segundo eles, foi a língua Kaingang, pois o dialeto era diferente, dificultando as conversas em alguns momentos. Ambos referem que, em 1976, o governo federal mantinha as escolas com material escolar e merenda, o qual perdurou até 1994, quando ocorreu a municipalização das escolas indígenas. Em 2007, o Estado do Paraná passou a ser mantenedor das escolas indígenas e, nesse sentido, as respectivas instituições eram responsáveis pela contratação de funcionários, merenda e material escolar.

Segundo os relatos de José e Antônia, inicialmente, o número de alunos matriculados era pequeno, pois muitos moravam longe e não tinham a obrigação de estudar. As disciplinas eram semelhantes às da escola não indígena, com o acréscimo da língua materna. No entanto era

\footnotetext{
${ }^{2}$ Segundo Jacques Le Goff (1994), a memória é a propriedade de conservar certas informações, propriedade que se refere a um conjunto de funções psíquicas que permite ao indivíduo atualizar impressões ou informações passadas, ou reinterpretadas como passadas. Para o mesmo autor, a memória não é apenas individual, mas também coletiva, composta pelas lembranças vividas pelo indivíduo ou que lhe foram repassadas, mas que não the pertencem somente, e são entendidas como propriedade de uma comunidade, um grupo. Muito própria de sociedades sem escrita, a atitude de lembrar é constante, e a memória coletiva confunde História e mito. Tais sociedades possuem especialistas em memória que têm o importante papel de manter a coesão do grupo.

${ }^{3}$ Nomes fictícios.

${ }^{4}$ Nome fictício.
}

INTERAÇÕES, Campo Grande, MS, v. 19, n. 4, p. 757-771, out./dez. 2018 
cobrado dos alunos o domínio da língua portuguesa para continuar nos estudos. Muito pouco trabalho era realizado para manutenção da cultura Kaingang, pois este não era o objetivo da escola naquele momento. O principal objetivo era ensinar os alunos a falar e escrever a língua portuguesa.

Carneiro da Cunha (2009) escreve que muitas ações governamentais com apoio da igreja, escolas e organizações não governamentais causaram interferências nos modos tradicionais dos povos indígenas do Brasil, sendo que essa luta em desestruturar a cultura indígena perdura desde 1500. Portanto não é estranho que hábitos tradicionais dos povos indígenas estejam em muitos casos esquecidos, pois foram empenhados esforços para incorporar os indígenas à sociedade brasileira. O discurso dos professores José e Antonia descreve essa realidade, pois foram orientados, desde sua formação como monitores, a seguir regras oriundas da mantenedora da escola.

Em relação à alimentação, Dona Maria considera que a base era coleta, caça, pesca e pequenas agriculturas realizadas geralmente em grupos familiares, de onde eram originados os pratos típicos.

Quando lembro de minha infância, lembro com saudades, em casa tinha tudo que precisava, meu pai, minha mãe, meus irmãos, os meus avós, tios e primos moravam perto de casa, éramos uma grande família. Quando o meu pai fazia o pari ${ }^{5}$, ficávamos eu, meus irmãos e meus primos esperando o pari encher. Depois íamos para casa limpar e assar pra comer com pisé $e^{6}$ parecia uma festa. Eu, meus irmãos e primos íamos para o mato fazer arapuca, armadilha para pegar passarinho era muito divertido, os meninos matavam os passarinhos e as meninas limpavam para assar, era assim que nós brincávamos. [...] Minha mãe e meu pai tinham um poió 7 , e plantavam milho de índio que minha mãe fazia a canjica e a farinha. Da farinha era feito farinha torrada (biju), o emir (bolo) e o pisé, e tudo que a gente comia tinha biju, o emĩ ou pisé para comer junto, com o que tínhamos. Os meus pais ensinavam pra gente as plantas, as frutas e as raízes que podíamos comer, mas para a gente aprender tínhamos que ir junto com eles toda vez que eles iam procurar comida. (Dona Maria, anciã da Terra Indígena Rio das Cobras).

Segundo Antonia, a alimentação consistia em:

[...] milho azedo com carne de caça assada na brasa, como veado, capivara, cateto e o peixe, o pisé que é o milho torrado, folhas e raízes na sua maioria parecidas com as que eu já conhecia, coró de palmito e o de outras arvores, o mel. Na sede do posto indígena ficava o escritório da Funai, onde o chefe do posto organizava plantação de arroz, feijão e milho, para a comunidade, também criavam gado e porcos, para ser compartilhado com a comunidade. (Antonia, professora indígena da Terra Indígena Rio das Cobras).

Dos processos de aquisição de alimentos dos povos indígenas no início da colonização, Cascudo $(1967 ; 1972 ; 1983)$ descreve que a carne era resultado da caça e da pesca onde a carne obtida era preferencialmente assada, as folhas coletadas eram cozidas em ebulição, as raízes e frutas eram assadas de maneira a acentuar o sabor adocicado. A aquisição de alimentos era marcada pela caça, pesca, coleta e alguma agricultura ao redor das moradias tais como milho, mandioca e batata doce. A partir do contato com o não indígena, as dinâmicas socioambientais de aquisição de alimentos foram modificadas e alimentos desconhecidos até então passaram a fazer

\footnotetext{
${ }^{5}$ Armadilha para pegar peixe, feito com taquara trançada e deixada em pontos estratégicos do rio.

6 Farinha feita de milho torrado com cinza (esse processo é necessário para que o milho não queime) e depois socado no pilão. Por último, é preciso peneirar a farinha para que as cinzas saiam.

7 Paiol, lugar onde eram realizados roçados, geralmente longe das comunidades.

${ }^{8}$ Bolo feito com milho verde ralado e deixado para azedar um pouco, depois assado na brasa.
} 
parte do hábito alimentar indígena. Está-se falando, portanto, de mudanças na cultura alimentar, oriundas de um processo de colonização e integração dos povos indígenas na sociedade nacional.

Nesse sentido, Dona Maria afirma que muita coisa ainda é utilizada na sua alimentação e de sua família, mas não são todos que comem, e refere que "as crianças e os jovens comem a maioria das vezes na escola, e ficam a maioria das vezes lá, então comem mais comida dos fóg (não indígena) e quando chegam em casa não sentem fome". Outros fatores que interferem na economia Kaingang, segundo Dona Maria, são os direitos como Bolsa Família e aposentaria "quando os véios vão para a cidade buscar o dinheiro do aposento, vai a família toda e como tem dinheiro para comprar as coisas, as crianças gostam de comer comida da lanchonete ou restaurante, e fazer compras no mercado".

Com a influência não indígena nos modos de vida dos povos indígenas, a obtenção dos alimentos atualmente se dá pela utilização de novas formas e técnicas de produção como a piscicultura e a pecuária. Outro fator importante é a aquisição comercial dada pela obtenção de recursos monetários adquiridos através de venda de artesanatos, algumas produções agrícolas, trabalho remunerado, benefícios sociais, doações voluntárias e sociais e a alimentação escolar, que também fazem parte dessa nova realidade indígena. Tais mudanças acarretam o consumo de alimentos até então desconhecidos dos indígenas, incluindo espécies vegetais e animais. Outro agravante é a inclusão massiva de alimentos processados, como sal, açúcar, embutidos, enlatados, em suas dietas cotidianas (LEITE, 2007).

Ao fazer uso de mercadorias e produtos industrializados, o quadro de saúde indígena passa a ser modificado, causando doenças como diabetes, hipertensão arterial e sobrepeso. "Desde o descobrimento, o contato com os não índios traz doenças que matam muitos índios, sendo as primeiras causas de uma enorme redução da população indígena" (SAAD, 2005 , p. 17).

Segundo Contreras e Gracia (2004) a globalização tem ordem econômica e política, ou seja, as mudanças de hábitos socioeconômicos e culturais são almejados pelas indústrias nacionais e internacionais. Esta não é uma realidade que envolve apenas os povos indígenas, mas toda a sociedade. A globalização tem por finalidade homogeneizar os indivíduos com a utilização de mercadorias e produtos.

Para os mesmos autores, a cultura alimentar é resultado da interação do homem com o seu meio, resultando na culinária (entendida como conjunto de regras por onde o alimento percorre um trajeto para ser absorvido como cultura). Dessa forma, tentam explicar como ocorrem os processos de inovação alimentar e alegam que, para que um alimento estranho ou estrangeiro seja adotado, não basta apenas que esteja disponível, mas que outros fatores devem ser considerados. É necessário, por exemplo, que um grupo de prestigio o adote, ou que um grupo dominante o imponha, ou ainda, que algumas autoridades científicas o recomendem. Por outro lado, o desaparecimento de hábitos culturais ocorre por transformações nos sistemas de valores culinários e alimentares, como, por exemplo, a colonização e aculturação. E por fim, as resistências acontecem por terem estruturas políticas e econômicas mais sólidas e uma cultura culinária mais elaborada.

Para melhor compreender essas transformações nas práticas alimentares nesse grupo indígena, bem como a miscigenação alimentar decorrente do encontro de culturas, descreve-se abaixo um pouco mais sobre o contexto escolar, instituição esta responsável por boa parte dessas mudanças. 


\subsection{Como a cultura alimentar Kaingang é tratada na escola?}

Segundo os primeiros professores indígenas das escolas da Terra Indígena Rio das Cobras, José a Antonia, a alimentação escolar na década de 1970 já se caracterizava como uma alimentação predominantemente não indígena.

Nós que preparávamos a merenda, com o que tinha, era macarrão com almôndega, arroz com feijão, achocolatado, bolacha salgada e doce. Fazíamos na cozinha da escola, os alunos eram poucos, então conseguíamos conciliar as aulas, com a cozinha e a limpeza da escola, tudo realizado por nós. De comida da cultura não tinha nada, pois tínhamos que fazer a merenda que mandavam nós fazer. Quem mandava nós fazer era o responsável pela educação da época, não lembramos o nome. Mas era assim, os alunos tinham que comer o alimento que era servido na escola, e assim os alunos cresceram comendo estes alimentos e se acostumaram, fazendo parte do dia a dia deles. Hoje vejo que muitos dos que foram meus alunos ainda comem o alimento tradicional, mas seus filhos ou netos não querem, porque na escola ainda é servida a comida não indígena. Nós também temos muitos dos alimentos não indígenas no nosso dia a dia, primeiro aprendemos a comer na nossa escola e comíamos por necessidade mesmo, depois tínhamos que preparar estes alimentos para os alunos porque mandavam nós fazer, e assim fomos nos habituando ao alimento não indígena. Na época não sabíamos que era importante fazer o alimento tradicional na escola, para manter a cultura, na nossa formação nunca falaram disso, pra falar a verdade não sabíamos nem para que servia a escola, nos trabalhávamos para garantir nosso sustento, fazíamos o que os chefes mandavam. (José e Antonia, professores indígenas da Terra Indígena Rio das Cobras).

Esse fragmento narrativo dá pistas do quanto a escola foi um lócus de imposições do colonizador aos povos indígenas e, como tal, a serviço dos interesses do projeto colonizador. Segundo Backes (2014), pode ser vista como uma das instituições centrais para a assimilação das culturas indígenas, sendo marcada, portanto, por práticas sistemáticas de negação de suas identidades, com destaque para a proibição não só da língua materna, mas aqui também da perda de sua cultura alimentar.

Verifica-se que os professores não questionavam essa situação, pois, não percebiam as modificações que a escola estava fazendo nos modos de vida do alunado. Nesse momento, a escola não considerava importante manter e valorizar os hábitos culturais da comunidade local.

Seguindo no tempo e chegando ao momento desta pesquisa (2016), buscou-se analisar se essa conduta permaneceu ou se houve modificações. Estudando a proposta pedagógica das cinco escolas pesquisadas, percebe-se que o atual ordenamento político possui um caráter institucional e educacional voltado para a valorização cultural. Porém não são especificadas as áreas da cultura que serão abordadas no contexto escolar, dificultando o cumprimento efetivo de valorização, revitalização e resgate da cultura. Praticamente, esae ordenamento legal e político não é tão visível assim, o que pode significar que a escola ainda está em processo de adequação sobre sua função frente ao povo Kaingang.

Para melhor compreender a realidade das escolas indígenas, a Tabela 1 apresenta o número de matrículas, nível de ensino atendido, professores indígenas e não indígenas em cada uma das escolas pesquisadas. 
Tabela 1 - Atendimento, número de alunos e de professores indígenas e não indígenas em escolas localizadas na Terra Indígena Rio das Cobras, PR, em 2016

\begin{tabular}{c|c|c|c|c}
\hline Escolas & Atendimento & Alunos & $\begin{array}{c}\text { Professores } \\
\text { indígenas }\end{array}$ & $\begin{array}{c}\text { Professores } \\
\text { não-indígenas }\end{array}$ \\
\hline A & $\begin{array}{c}\text { Pré-escolar ao ensino médio e } \\
\text { educação de jovens e adultos }\end{array}$ & 272 & 11 & 23 \\
\hline B & $\begin{array}{c}\text { Pré-escolar ao ensino médio e } \\
\text { educação de jovens e adultos }\end{array}$ & 414 & 13 & 60 \\
\hline C & $\begin{array}{c}\text { Pré-escolar ao ensino médio e } \\
\text { educação de jovens e adultos }\end{array}$ & 297 & 09 & 40 \\
\hline D & $\begin{array}{c}\text { Pré-escolar ao ensino médio e } \\
\text { educação de jovens e adultos }\end{array}$ & 150 & 06 & 19 \\
\hline E & $\begin{array}{c}\text { Pré-escolar aos anos finais do } \\
\text { ensino fundamental e educação } \\
\text { de jovens e adultos }\end{array}$ & 52 & 04 & 154 \\
\hline Total & & 1.185 & 43 & \\
\hline
\end{tabular}

Fonte: Elaborado pelas autoras a partir dos dados disponibilizados pelas escolas (2017).

Esses dados revelam o número expressivo de alunos no ano de 2016, bem como o número de professores não indígenas nas escolas, se comparado ao número de professores indígenas. Apesar do relato positivo dos primeiros professores indígenas da Reserva (José e Antonia) sobre os avanços relativos à conclusão e formação superior dos índios, esse panorama ainda está sendo construído, pois ainda é pequeno o número dos que concluem o ensino superior e podem ser professores nessas escolas. Esse dado é importante para o objeto deste estudo, pois os professores não indígenas podem estar traduzindo em suas atitudes seus modos próprios de ver, perceber e atuar sobre o mundo, pois não vivenciam as práticas indígenas como um indígena. Além disso, desde que as escolas indígenas foram implantadas, valorizaram-se conhecimentos não indígenas, e estes se tornaram gradativamente mais presentes no cotidiano.

Esses dados, projetos pedagógicos mal elaborados e não efetivados e presença predominante de professores não indígenas, podem não explicar totalmente as forças de aculturação favorecendo a influência da maioria sobre a minoria, mas podem ser um de seus fatores. Todavia é importante não desconsiderarmos as peculiaridades de cada escola, bem como o grau de envolvimento da comunidade onde a escola está instalada.

Por outro lado, no que tange aos demais profissionais que atuam na educação escolar, verifica-se que todos os técnicos administrativos, serviços gerais e merendeiras são indígenas. Aqui cabe pontuar que todos os funcionários indígenas e não indígenas atuantes nas escolas passam anualmente por análise da comunidade, onde a atuação profissional é verificada de acordo com o cumprimento de regras e normas estabelecidas em reuniões realizadas antes do contrato.

Diante disso, é possível verificar que o quadro funcional das escolas está aos poucos se enquadrando nos critérios de uma escola indígena, ou seja, dirigida por profissionais indígenas que conhecem e vivem a realidade e, portanto, estão construindo uma escola de acordo com essa realidade.

Em relação à cozinha das escolas, foi possível perceber, por meio da observação e dos relatos das merendeiras, que todas são padronizadas e não diferem das cozinhas das escolas não indígenas. No entanto nenhuma delas apresentou infraestrutura adaptada ao preparo de alimentos tradicionais, já que a maioria dos alimentos Kaingang é preparado direto na brasa ou 
sobre ela. Ao questionar as merendeiras sobre qual a visão que tinham sobre a cultura alimentar, todas foram unânimes em afirmar que não percebiam a importância das escolas para a manutenção e valorização de sua cultura alimentar. Além disso, colocaram a dificuldade de preparar os pratos típicos, já que grande parte dos produtos alimentícios disponíveis na escola não faz parte da cultura Kaingang e a infraestrutura da cozinha não correspondia ao preparo desse tipo de culinária.

Quanto aos pais e lideranças, ao serem questionados sobre suas opiniões relativas à cultura alimentar, demonstraram a poio à valorização, revitalização e o resgate da cultura alimentar, porém não sabiam como ajudar para que isso fosse efetivado no âmbito escolar. Notou-se a preocupação dos entrevistados sobre a questão do preparo dos pratos típicos na escola, porém, no decorrer das entrevistas, demonstraram-se inaptos para vislumbrar uma solução.

Essa situação pode ser resultado da valorização da alimentação não indígena na escola ao longo dos anos, impondo-se sobre a cozinha Kaingang, assim como todos os seus processos culturais. Apesar do passado anulador da cultura, atualmente o Kaingang tem estado mais frequentemente em lutas sobre a afirmação de sua identidade e reivindicação de seus direitos. Tais avanços estão se dando pelo conhecimento de leis que asseguram as especificidades culturais e a sua preservação (BACKES, 2014). No entanto o termo 'cultura alimentar' ainda é novidade entre os entrevistados.

Sobre os alimentos oferecidos na alimentação escolar, verifica-se que, comparativamente aos das décadas passadas (desde 1970), não ocorreram mudanças que apontassem para a valorização da cultura indígena, como se pode constatar no Quadro 1.

Quadro 1 - Lista de gêneros alimentícios disponibilizados nas escolas indígenas da Terra Indígena Rio das Cobras, PR, 2016

\begin{tabular}{|l|l|}
\hline $\begin{array}{l}\text { Gêneros } \\
\text { Alimentícios } \\
\text { Convencionais }\end{array}$ & $\begin{array}{l}\text { achocolatado em pó, açúcar cristal, açúcar extra fino, alho e cebola triturados } \\
\text { (secos), arroz mix, arroz parboilizado, arroz polido, biscoito maisena integral, } \\
\text { biscoito cookie, biscoito cream cracker integral, canjica branca cozida c/ sache } \\
\text { de leite em pó, cereal de milho natural, ervilha em conserva, farinha de milho } \\
\text { (biju), feijão carioca cozido, feijão preto cozido, leite em pó integral instantâneo, } \\
\text { macarrão caracollini-grano duro, macarrão curva bengal - sêmola com ovos, } \\
\text { macarrão espaguete-grano duro, macarrão integral-tipo penne, milho verde em } \\
\text { conserva, molho de tomate, óleo de soja refinado, sal não refinado (marinho), } \\
\text { chá mate, composto lácteo. }\end{array}$ \\
\hline $\begin{array}{l}\text { Gêneros } \\
\text { Alimentícios } \\
\text { da Agricultura }\end{array}$ & $\begin{array}{l}\text { abóbora desc/pic/ embalada a vácuo, acelga, bolacha caseira, cuca/bolo simples, } \\
\text { abobrinha verde, alface, banana caturra, batata doce, cebolinha verde, almeirão, } \\
\text { limão, suco de uva integral, suco de maça integral, couve manteiga, beterraba, } \\
\text { Falsinha, brócolis, laranja pera, cenoura, chuchu, repolho, poncã, mexerica/ } \\
\text { murcote, vagem, quirera, abacate, mandioca picada embalada a vácuo. }\end{array}$ \\
\hline $\begin{array}{l}\text { Gêneros } \\
\text { alimentícios } \\
\text { perecíveis }\end{array}$ & $\begin{array}{l}\text { almôndega bovina assada ou cozida congelada, carne bovina em cubos ou } \\
\text { tiras congelada, carne suína congelada - pernil s/ osso em cubos, file de cação } \\
\text { congelado, filé de peito de frango em cubos, filé de polaca do Alasca congelado, } \\
\text { ovo de galinha tipo 2, salsicha de frango. }\end{array}$ \\
\hline
\end{tabular}

Fonte: Elaborado pelas autoras a partir dos dados oferecidos pelas escolas investigadas e Núcleo Regional de Educação (2017).

Segundo a nutricionista responsável pela alimentação escolar no estado do Paraná- "cada aldeia tem liberdade de elaborar e compor o cardápio conforme hábitos locais". No entanto, 
analisando a lista de produtos disponibilizados, dificilmente poderia se compor um cardápio que respeitasse a cultura alimentar Kaingang. Isso é confirmado pelos próprios diretores, que afirmam não ser possível adaptar o cardápio por falta de produtos alimentícios ofertados pelo estado afins à cultura alimentar Kaingang.

É pertinente destacar que, apesar de alguns desses alimentos tradicionais estarem incluídos no cardápio (feijão, biju, quirera, canjica, mandioca e o peixe), estes são preparados de maneira não indígena. Além disso, nenhum deles se constitui como alimento fresco ou sem processamentos a exemplo do peixe que, além de não ser fresco, não é o tipo mais comumente utilizado ou típico da região, ao contrário - um deles é proveniente do Alasca.

É importante salientar que um dos motivadores da descentralização do Programa Nacional de Alimentação Escolar (PNAE), que ocorreu a partir de 1994, era o respeito aos hábitos alimentares e à vocação agrícola de cada local. No Artigo 2o da Lei 11.947/2009, consta que uma das diretrizes do Programa é o respeito à cultura e às tradições alimentares.

Além disso, um dos avanços significativos para as minorias em relação à alimentação escolar teve início de 2003 quando os alunos indígenas e quilombolas passaram a receber um valor per capita maior que o da sociedade envolvente. Em 2009, o Artigo 14 da Lei n. 11.947 propôs ainda que, do total dos recursos financeiros repassados pelo Fundo Nacional de Desenvolvimento da Educação (FNDE), no âmbito do PNAE, no mínimo 30\% (trinta por cento) deveriam ser utilizados na aquisição de gêneros alimentícios diretamente da agricultura familiar e do empreendedor familiar rural ou de suas organizações, priorizando-se os assentamentos da reforma agrária, as comunidades tradicionais indígenas e comunidades quilombolas.

A despeito da aquisição dos produtos alimentícios para as escolas, esta é realizada por meio de processos licitatórios de acordo com critérios previstos na legislação vigente. Em relação às compras de Agricultores Familiares, e comunidades tradicionais como os indígenas, a nutricionista responsável considera que ainda há desafios para tanto.

Toda a compra é centralizada. É feita pela gestão do programa. Dentro deste contexto, o PNAE possui regras claras a respeito da alimentação indígena, bem como recurso diferenciado para esse atendimento. A realidade é de que há muita diversidade entre as aldeias, onde algumas têm o hábito bem marcado e em outras já se observa que está bem globalizado usam preparações idênticas de outras escolas. [...] Apesar de haver prioridade para aquisição de agricultura familiar de indígenas, quilombolas, assentados, em sete anos de aquisição, nunca houve proposta ou contrato de alimentos produzidos por indígenas. Fala-se que isso decorre da cultura extrativista e não produtora. O nosso departamento de Diversidade tem articulado com as aldeias essa possibilidade de comercialização para o PNAE". (Nutricionista responsável pelas escolas da Terra Indígena Rio das Cobras).

Evidencia-se que, corroborando outros estudos realizados no país com indígenas (CASTRO et al., 2014; GONÇALVES, 2012), não há diferenciação dos cardápios ou pauta de gêneros alimentícios disponibilizados entre indígenas e não indígenas, enfraquecendo a cultura indígena.

Para além do cardápio escolar, segundo os relatos dos diretores, em linhas gerais, nas cinco escolas, há atividades que buscam resgatar pratos tradicionais por meio de projetos realizados principalmente na semana do Dia do Índio ou quando o professor de língua materna realiza projetos de acordo com o currículo da disciplina. Ou seja, a cultura alimentar não é valorizada cotidianamente, mas em momentos específicos. No caso desses momentos festivos, as escolas realizam apresentações de varias áreas da cultura, onde a cultura alimentar é contemplada, porém, o almoço coletivo é complementado com alimento não indígena, com direito a churrasco, 
maionese, pão francês e refrigerante. Ainda, algumas dessas datas comemorativas da sociedade não indígena foram inseridas e são celebradas no contexto escolar, tais como Páscoa, Festa Junina, Natal e até o Dia das Bruxas, demonstrando que os indígenas são expostos a outras culturas..

Essas constatações concordam com os apontamentos feitos por Contreras e Gracia (2004), que consideram que, com os fluxos migratórios e com o encontro de culturas distintas, é de se esperar que a mestiçagem alimentar, com diferentes níveis de intercâmbio e aculturação, continue tendo lugar. Para os autores, identidades autóctones se manterão e reconstruirão cada vez mais em celebrações festivas e menos nas cozinhas cotidianas. Cotidianamente, observa-se a prevalência de práticas materiais e simbólicas originárias dos contatos interculturais e do processo global de industrialização socioeconômica.

\section{CONSIDERAÇÕES FINAIS}

Este artigo buscou analisar o papel do ambiente escolar na cultura alimentar Kaingang na Terra Indígena Rio das Cobras, PR, e identificou que o Kaingang, ao longo dos anos, tem sofrido influências não indígenas decorrentes da implantação da escola e das políticas de integração. As consequências repercutiram e ainda repercutem nas relações que o Kaingang tem com sua cultura.

Nesse sentido, ao avaliar a cultura alimentar, constatou-se que o assunto não tem tido grande relevância por parte da comunidade escolar, os quais consideram o alimento não indígena servido nas escolas como 'normal', não o identificando como marcador de identidade nem como um processo no qual seus hábitos estão sendo transformados a partir da inclusão de outra cozinha e de outros sabores.

A miscigenação ocorre sub-repticiamente e silenciosamente em um ambiente (a escola), onde o cotidiano alimentar ainda não foi considerado pelos que nele convivem como uma ameaça que perpetua inovações alimentares e impõe a cultura não indígena por meio de outras cozinhas. Ao contrário do que se esperaria, esse ambiente traz culturas que vão desde o Alasca (com a oferta de pescados na alimentação escolar) até os Estados Unidos e suas festas típicas (Dia das Bruxas), deixando para trás suas festas folclóricas, suas danças, suas músicas, seus costumes, sua cozinha. Esta agora se apresenta apagada em meio a pratos de maionese, pão francês e refrigerante, em apenas uma vez ao ano- dia em que se comemora o Dia do Índio.

Embora as memórias continuem vivas entre os mais idosos e a cultura alimentar indígena também tenha deixado suas marcas nos hábitos não indígenas com seus pratos como o churrasco, o pinhão e o chimarrão (só para citar alguns), evidencia-se claramente nesta pesquisa a perda da cultura alimentar indígena, especificamente a dos Kaingang. Mais problemático ainda, o quanto a escola tem sido cúmplice nesse empobrecimento, mesmo com todo um discurso de valorizar as diferenças e manter vivos os distintos modos de vida e de identidade alimentar.

Assim, é necessário que outras pesquisas sejam feitas com as diversas etnias indígenas existentes no país, para que se possa evidenciar cada vez mais a necessidade de repensar a manutenção da riqueza cultural que se tende a perder com os movimentos de homogeneização.

\section{REFERÊNCIAS}

ALARCÃO, Isabel. Escola reflexiva e nova racionalidade. Porto Alegre: Artmed, 2001.

ALMEIDA, Antonio Cavalcante. Organização Kaingang: o caso das lideranças tradicionais e políticas no Paraná. Revista Ciências Sociais em Perspectiva, Cascavel, PR, v. 13, n. 25, 2014. 
ALTIERI, Miguel. Agroecologia: bases científicas para uma agricultura sustentável. São Paulo: Expressão Popular; Rio de Janeiro: AS-PTA, 2012. 400p.

ARAÚJO, Rita de Cássia; FAUSTINO, Rosangela Célia; NOVAK, Maria Simone Racomini. Memórias, conhecimentos e literatura na Escola Indígena Guarani Nhandewa. In: CONGRESSO NACIONAL DE EDUCAÇÃO - EDUCERE, 9. ENCONTRO SUL BRASILEIRO DE PSICOPEDAGOGIA, 3. Curitiba: PUC-PR, out. 2009. Disponível em: <http://www.educadores.diaadia.pr.gov.br/arquivos/File/educacao_indigena/ memorias_conhecimentos_literatura_escola.pdf>. cesso em: 26 mar. 2016.

BACKES, José Licínio. A escola indígena intercultural: espaço/tempo de afirmação da identidade étnica e de desconstrução da matriz colonial. Interações, Campo Grande, MS, v. 15, n. 1, p. 13-9, jan./jun. 2014.

BECKER, Ítala Irene Basile. O índio Kaingang no Rio Grande do Sul. São Leopoldo, RS: Instituto Anchietano de Pesquisas, 1976. 334 p. (Pesquisas Antropologia, 29).

BRASIL. Saúde indígena: uma introdução ao tema. Brasília: Ministério da Educação, Secretaria de Educação Continuada, Alfabetização, diversidade e Inclusão, 2012.

. Lei n. 11.947, de 16 de junho de 2009. Dispõe sobre o atendimento da alimentação escolar e do Programa Dinheiro Direto na Escola aos alunos da educação básica. Disponível em: <http://www. planalto. gov.br/ccivil_03/_ato2007-2010/2009/lei//11947.htm>. Acesso em: 26 mar. 2016.

. Educação Escolar Indígena: diversidade sociocultural indígena ressignificando a escola. Brasília, DF: Cadernos Secretaria de Educação Continuada, Alfabetização e Diversidade (Secad/MEC), 2007.

. Referencial curricular nacional para as escolas indígenas. Brasília, DF: Ministério da Educação e do Desporto, Secretaria de Educação Fundamental, MEC/SEF, 1998.

. LDB. Lei 9.394/96 - Lei de Diretrizes e Bases da Educação Nacional. 1996. Disponível em: <http:// www.planalto.gov.br/CCIVIL_03/leis/L9394.htm>. Acesso em: 12 abr. 2015.

Constituição da República Federativa do Brasil. Brasília, DF: Departamento de Publicações, Senado Federal, 1988. Disponível em: <http://www.planalto.gov.br/ccivil_03/Constituicao/Constituicao. htm>. Acesso em: 9 mar. 2015.

CAPORAL, Francisco Roberto; COSTABEBER, José Antonio; PAULUS, Gervásio. Agroecologia: matriz disciplinar ou novo paradigma para o desenvolvimento rural sustentável. Brasília, DF, 2006. Disponível em: <http://www.reformaagrariaemdados.org.br/sites/default/files/Agroecologia,\%20Matriz\%20 disciplinar\%20ou\%20novo\%20paradigma\%20-\%20Francisco\%20Caporal,\%20Jose\%20Costabeber,\%20 Gervasio\%20Paulus.pdf>. Acesso em: 9 mar. 2015.

CARNEIRO DA CUNHA, Manuela. Etnicidade: da cultura residual, mas irredutível. In: Cultura com Aspas. São Paulo: Cosac Naify, 2009. p. 235-44.

CASCUDO, Luiz da Câmara. História da alimentação no Brasil: cozinha brasileira. Belo Horizonte: Itatiaia; São Paulo: Ed. da Universidade de São Paulo, 1983. v. 2.

Seleta. Rio de Janeiro: José Olympio, 1972.

História da alimentação no Brasil: cardápio indígena, dieta africana, ementa portuguesa. São Paulo: Companhia Editora Nacional, 1967. v. 1.

CASTRO, Teresa Gontijo et al. Características de gestão, funcionamento e cardápios do Programa Nacional de Alimentação Escolar em escolas Kaingang do Rio Grande do Sul, Brasil. Cadernos de Saúde Pública, Rio de Janeiro, v. 30, n. 11, p. 2401-12, nov. 2014.

CONTRERAS, Jesus; GRACIA, Mabel. Alimentacion y cultura: perspectivas antropológicas. Barcelona: Ariel, 2004.

D'ANGELIS, Wilmar R.; VEIGA, Juracilda. Habitação e acampamentos Kaingang hoje e no passado. Revista Cadernos do Ceom, Chapecó, SC, n. 18, p. 213-42, 2003.

DEAN, Warren. A ferro e fogo: a história e a devastação da Mata Atlântica brasileira. 1. ed. São Paulo: Cia. das Letras, 2004. 484p. 
ENGEL, Vonia; ALMEIDA, Giovana Goretti Feijó de. A cultura no processo contemporâneo de transformação tecnológica na articulação com o desenvolvimento regional. Espaço Plural, Cascavel, PR, ano XVI, n. 32, p. 224-42, 10 Semestre 2015.

FAGUNDES, Luiz Fernando Caldas; FARIAS, João Maurício (Org.). Objetos-sujeitos: a arte kaingang como materialização de relações. Porto Alegre: FUNAI/CR; Passo Fundo/CTL; Porto Alegre: Editora Deriva, 2011.

GONÇALVES, Renata da Cruz. A diversidade sociocultural no Programa Nacional de Alimentação Escolar: uma etnografia da alimentação escolar indígena entre os Xavánte de Parabubure, Mato Grosso. 2012. Dissertação (Mestrado em Nutrição) - Universidade Federal de Santa Catarina (UFSC), Florianópolis, 2012.

IANDÉ. Índios Xetá. Boletim n. 27, jan. 2008. Disponível em: <http://www.arara.fr/BBTRIBOXETA.html>. Acesso em: 20 set. 2016.

INSTITUTO BRASILEIRO DE ECONOMIA E ESTATÍSTICA (IBGE). Censo Demográfico 2010. Disponível em: $<$ https://cidades.ibge.gov.br/brasil/pr>. Acesso em: 15 out. 2016.

LE GOFF, Jacques. História e memória. Campinas, SP: Ed. Unicamp, 1994.

LEITE, Mauricio Soares. Transformação e persistência: antropologia da alimentação e nutrição de uma sociedade indígena amazônica. Rio de janeiro: Editora Fiocruz, 2007.

MEIHY, Jose Carlos Sebe Bom. Manual de história oral. 5. ed. São Paulo: Edições Loyola, 2005.

MONIOT, Henri. A história dos povos sem história. In: LE GOFF, Jacques (Org.). História: novos problemas. Rio de Janeiro: F. Alves, 1988.

MOREIRA, Roberto José. Críticas ambientalistas à Revolução Verde. Estudos Sociedade e Agricultura, Rio de Janeiro, n. 15, p. 39-52, 2000.

PINHEIRO, Maria Helena de Amorin. A emergência do ritual do kiki no contexto contemporâneo. 2013, 191 f. Dissertação (Mestrado em Antropologia Social) - Universidade Federal do Paraná (UFPR), Curitiba, 2013.

PORTO ALEGRE. Povos indígenas na Bacia Hidrográfica do Lago Guaíba. Porto Alegre, Rio Grande do Sul, Brasil. Secretaria Municipal de Direitos Humanos e Segurança Urbana. Coordenação de Direitos Humanos. Porto Alegre: Prefeitura de Porto Alegre, 2008.

ROCHA, Rodrigo Veras. A ausência de Laudo Pericial Antropológico como causa de nulidade absoluta nos processos criminais em que o índio figure como réu. 2008. 94 f. Monografia (Bacharelado em Direito)Universidade do Vale de Itajaí (Univali), São José, SC, 2008. Disponível em: <http://siaibib01.univali.br/ pdf/Rodrigo\%20Veras\%20Rocha.pdf>. Acesso em: 24 dez. 2016

SAAD, Mariane Barbosa Nogueira. Saúde e nutrição Terena: sobrepeso e obesidade. 2005. 129 f. Dissertação (Mestrado em Saúde Coletiva) - Universidade Federal de Mato Grosso do Sul, Campo Grande, MS, 2005.

\section{Sobre as autoras:}

Suzana Kagmu Mineiro: Mestre em Agroecologia e Desenvolvimento Rural Sustentável. E-mail: sumineiro@bol.com.br

Rozane Marcia Triches: Professora Doutora do curso de graduação em Nutrição e do Programa de Pós-Graduação em Agroecologia e Desenvolvimento Rural Sustentável. E-mail: rozane.triches@gmail.com 
